\title{
Reaction of clubroot-resistant genotypes of Brassica rapa, Brassica napus and Brassica oleracea to Polish Plasmodiophora brassicae pathotypes in laboratory tests
}

\author{
Agnieszka Czajka (D) Monika Markiewicz $(\mathbb{D} \cdot$ Beata Kowalska (D) - Urszula Smolińska
}

Accepted: 17 August 2020 /Published online: 26 August 2020

(C) The Author(s) 2020

\begin{abstract}
The Brassica genotypes selected for the experiments were previously found to be resistant to various Plasmodiophora brassicae pathotypes $(\mathrm{Pb})$. Their interaction with pathotypes $\mathrm{Pb} 2, \mathrm{~Pb} 3$ and $\mathrm{Pb} 9$ isolated in Poland was studied, using macroscopic observation for the presence of root galls, microscopic observations of $P$. brassicae plasmodia in the root hairs and quantitative PCR for determination of the pathogen's quantity in plant roots and growing media. Of the Brassica genotypes studied, only B. rapa var. capitata line AABBcc was fully resistant to all the Polish pathotypes of $P$. brassicae. Some of the other "clubroot-resistant" genotypes tested were resistant to selected pathotypes, e.g. Brassica napus var. rapifera 'Wilhelmsburger' to $\mathrm{Pb} 2$ and $\mathrm{Pb} 3$, Brassica oleracea var. capitata 'Kilaton $\mathrm{F}_{1}$ ' to $\mathrm{Pb} 2$ and Brassica rapa subsp. pekinensis 'Bilko $\mathrm{F}_{1}$ ' to $\mathrm{Pb} 3$, but were susceptible to others. B. oleracea var. capitata 'Bindsachsener', B. oleracea var. acephala subvar. lacinata 'Verheul' and B. napus var. napus 'Mendel $\mathrm{F}_{1}$ ' were moderately to highly susceptible to all
\end{abstract}

A. Czajka

Departament of Phytopathology, Research Institute of Horticulture, Konstytucji 3 Maja 1/3, Skierniewice, Poland

M. Markiewicz $(\bowtie)$

Departament of Applied Biology, Research Institute of Horticulture, Konstytucji 3 Maja 1/3, Skierniewice, Poland e-mail: monika.markiewicz@inhort.p1

B. Kowalska · U. Smolińska

Departament of Microbiology, Research Institute of Horticulture, Konstytucji 3 Maja 1/3, Skierniewice, Poland
Polish P. brassicae pathotypes. These results show that the classification of virulence of $P$. brassicae pathotypes selected in various areas differs significantly toward the same Brasssica genotypes and puts in question the practical value of pathotype classification determined with differential sets for farmers and plant breeders. Our results showed that B. rapa var. capitata AABBcc line, B. napus var. rapifera 'Wilhelmsburger', $B$. oleracea var. capitata 'Kilaton $\mathrm{F}_{1}$ ', B. rapa subsp. pekinensis 'Bilko $\mathrm{F}_{1}$ ' could be considered in Brassica breeding programmes as a source of resistance to Polish $P$. brassicae isolates.

Keywords Brassica genotypes · Clubroot resistance · Plasmodiophora brassicae Pathotypes

\section{Introduction}

Clubroot is a very dangerous disease affecting most of Brassica species and many other cruciferous plants. Its causative agent is the obligate parasite Plasmodiophora brassicae Wor. (Dixon 2009). The pathogen has a complex life cycle comprising three stages: 1) root hair infection by resting spores present in soil, 2) cortical infection, and 3) formation of resting spores and their release to the soil from decaying root galls (Kageyama and Asano 2009; McDonald et al. 2014). The primary phase of the life cycle of $P$. brassicae (root hair infection) occurs in both susceptible and resistant cultivars of host species, and even in non-host plants (Deora et al. 2013). However, the infection rate and further development of the pathogen in root hairs differ among Brassica 
species, with development occurring quicker in susceptible lines and slower in the resistant ones. Characteristic disease symptoms appear on roots in the form of irregular galls, initially small, light yellow and fragile and then dark and decaying. Diseased tissues lose their ability to uptake water and nutrients from the soil, which results in wilting and stunting of the above ground part of plants (Strelkov et al. 2006). Decaying diseased roots release resting spores into the soil, where they can remain viable for at least 20 years (Dixon 2009).

The disease causes severe losses on cruciferous vegetable and rapeseed plantations in Poland and worldwide (Robak 1991; Wallenhammar 1996; Dixon 2014). Depending on soil conditions, infestation rate, pathogenicity of $P$. brassicae local strains and susceptibility of a crop's variety, yield losses can range from $30 \%$ to even $100 \%$ (Wallenhammar 1996). In control of the disease, the most important are preventive treatments including usage of pathogen-free fields, early pathogen detection, non-host crop rotation, use of the bait, decoy or catch crops, maintaining the appropriate soil $\mathrm{pH}$ and soil drenches with fungicides (Murakami et al. 2000; Peng et al. 2014; Hwang et al. 2015). However, these methods would not reduce clubroot severity in heavily infested fields and they are not cost effective. Besides, soil drenches with fungicides have a very negative impact on the environment. Thus, the use of resistant varieties is considered as the most efficient method for control of the disease (Rahman et al. 2014). However, the choice of resistant cultivars is limited and the varietal resistance can be easily broken due to high pathogenic variability of $P$. brassicae (Diederichsen et al. 2014). Therefore, resistance to clubroot is one of the mayor tasks in Brassica breeding programmes.

P. brassicae consists of numerous physiological pathotypes (races), differing in their ability to infect specific host genotypes (Robak 1991). Several sets of plant hosts have been proposed to determine these pathotypes (Williams 1966; Buczacki et al. 1975; Strelkov and Hwang 2014). The most commonly used is European Clubroot Differential Set (ECD), developed by Buczacki et al. (1975), which consist of three subsets: B. rapa (five hosts), B. napus (five hosts) and $B$. oleracea subset (five hosts) and allows to select different pathotypes of $P$. brassicae. The differential set proposed by Williams (1966) uses four differential genotypes: B. napus (two host) and B. oleracea (two host), which can differentiate sixteen pathotypes. The pathogenicity of $P$. brassicae pathotypes is highly variable within and between field populations. According to Robak (1991), in Poland the most common are pathotypes 2, 3 and 9.

In clubroot resistance breeding programs it is of a great importance to evaluate the available sources of resistance. There are several resistant Brassica species and cultivars harbouring resistance genes, but their resistance may vary depending on a pathotype of the pathogen. The aim of this study was: 1) to evaluate the degree of resistance of several Brassica genotypes carrying various resistance genes to Polish isolates of $P$. brassicae by the use of micro- and macroscopic observation of the disease symptoms and molecular tests of the presence of spores in roots of the tested plants; and 2) to determine whether cultivation of selected plants can lead to the reduction of the pathogen's quantity in the soil.

\section{Materials and methods}

\section{Plant material}

The experiments were done on five genotypes of $B$. oleracea, B. napus and B. rapa, selected from European Clubroot Differential Set, and on three commercial cultivars. These genotypes have been found to be highly resistant to several $P$. brassicae pathotypes (Kuginuki et al. 1999; Diederichsen et al. 2006; Strelkov et al. 2006; Cebula et al. 2010; Cao et al. 2014) and are recommended as a source of resistance traits in breeding (Hasan et al. 2012). The Chinese cabbage (B. rapa ssp. pekinensis) cv. Granaat, extremely susceptible to all known pathotypes of clubroot (Kopecký et al. 2012), was used as a negative control for resistance to clubroot. The list of the genotypes used in the study is presented in Table 1. The seeds of genotypes belonging to European Clubroot Differential Set (ECD) were obtained from the Horticulture Research International, Genetic Resources Unit (Wellesbourne, Warwick, UK). The seeds of Chinese cabbage (B. rapa subsp. pekinensis) cv. Bilko $F_{1}$ were purchased from Bejo Seeds Inc. (Konotopa, Poland) and seeds of headed cabbage (B. oleracea var. capitata) cv. Kilaton $\mathrm{F}_{1}$ and rapeseed (B. napus var. napus) cv. Mendel $\mathrm{F}_{1}$ were obtained from the collection of Research Institute of Horticulture (Skierniewice, Poland). 


\section{Source of the $P$. brassicae isolates}

Infected root samples, with visible galls, were collected from the commercial plantations of Brassica oleracea var. capitata cv. Kamienna Głowa located in various parts of Poland. The samples were washed, cleaned, air dried and catalogued. The pathotypes of the isolates were determined as $P$. brassicae $(\mathrm{Pb}) 2,3$ and 9 based on the reaction of the four genotypes included in differential set of Williams (1966) to the pathogen (Table 2).

Inoculum preparation

Spore suspension was prepared as described by Voorrips (1992). The clubbed roots were homogenized with distilled water (1:3, w:v) at high speed in a mechanical blender. The suspension was filtered four times through 5 layers of cheesecloth. The spore concentration in the filtrate was quantified in haemocytometer and was adjusted to approximately $10^{8}$ spores per $\mathrm{mL}$ through dilution with sterile distilled water. Obtained spore suspension was stored at $4{ }^{\circ} \mathrm{C}$ until use. To propagate these pathotypes for further studies, seeds of the susceptible B. rapa $\mathrm{cv}$. Granaat were sown in growing medium inoculated with resting spores $\left(10^{7}\right.$ spores per $\mathrm{mL}$ of the medium) of each $P$. brassicae pathotype and grown in a greenhouse under 14-h light/10-h dark photoperiod at $22{ }^{\circ} \mathrm{C}$. After 5 weeks of growth in the inoculated medium, the plants were dug out, cleaned and then the galls were separated and stored at $-20{ }^{\circ} \mathrm{C}$ until use.

Glasshouse bioassay of $P$. brassicae

resistance - Macroscopic observation

The growing medium used in the tests was prepared by mixing the peat substrate (Klasmann) at pH 5.2 with the
Table 2 Genotypes used to identify Plasmodiophora brassicae pathotypes according to Williams (1966)

\begin{tabular}{ll}
\hline ECD No. & Differential host \\
\hline ECD 10 & Brassica napus var. rapifera cv. Wilhelmsburger \\
ECD 11 & Brassica oleracea var. capitata cv. Badger Shipper \\
ECD 13 & Brassica oleracea var. capitata cv. Jersey Queen \\
- & Brassica napus var. napobrassica cv. Laurentian \\
\hline
\end{tabular}

low peat ( $\mathrm{pH}$ 5.9) in 1:1 proportion (v:v), and then sterilizing at $100{ }^{\circ} \mathrm{C}$ for $20 \mathrm{~min}$. After 2 weeks, the resting spore suspension of $P$. brassica pathotypes $\mathrm{Pb} 2, \mathrm{~Pb} 3$ and $\mathrm{Pb} 9$ was added to growing medium in quantity to obtain final spore concentration of about $10^{7}$ spores per $\mathrm{mL}$ and mixed thoroughly. The experiments were carried out in plastic trays filled with $2 \mathrm{~L}$ of inoculated growing media. The trays filled with noninoculated medium served as a control. 40 seeds from each genotype were seeded into the trays in three replicates. Plants were grown in a glasshouse under natural light, photoperiod $14-\mathrm{h} / 10 \mathrm{-h}$ and temperature $22{ }^{\circ} \mathrm{C}$. The growing medium moisture was maintained by regular watering. 10, 20 and 35 days after sowing the sample consisted of 10 randomly selected plants was uptaken, the roots were washed under the running water and blotted on paper towel. The occurrence of root galls was assessed individually on each plant on a 0-3 scale according to Buczacki et al. (1975) and Kuginuki et al. (1999), where: 0 - no symptoms visible on roots, 1 - single galls on lateral roots, 2 - numerous galls on lateral and/or main roots, 3 - distortion of the entire root system, uniform galls on the main root. The trials were conducted as a complete randomized block design with three replications per a treatment. For
Table 1 Genotypes used for micro- and macroscopic observation and for molecular tests

\begin{tabular}{|c|c|}
\hline Genotype & ECD number \\
\hline Brassica rapa var. capitata line AABBcc (turnip) & ECD 03 \\
\hline Brassica rapa ssp. pekinensis cv. Granaat (Chinese cabbage) & ECD 05 \\
\hline Brassica napus var. rapifera cv. Wilhelmsburger (swede) & ECD 10 \\
\hline Brassica oleracea var. capitata cv. Bindsachsener (headed cabbage) & ECD 12 \\
\hline Brassica oleracea var. acephala subvar. lacinata cv. Verheul (kale) & ECD 15 \\
\hline Brassica oleracea var. capitata $\mathrm{cv}$. Kilaton $\mathrm{F}_{1}$ (headed cabbage) & - \\
\hline Brassica rapa subsp. pekinensis cv. Bilko $\mathrm{F}_{1}($ Chinese cabbage $)$ & - \\
\hline Brassica napus var. napus cv. Mendel $\mathrm{F}_{1}$ (rapeseed) & - \\
\hline
\end{tabular}


statistical analysis, disease index (ID) for each genotype was calculated, using the formula of Strelkov et al. (2006):

$$
\mathrm{ID}=\frac{\sum(\mathrm{n} \times 0+\mathrm{n} \times 1+\mathrm{n} \times 2+\mathrm{n} \times 3)}{N \times 3} \times 100 \%
$$

where: $n$ is the number of plants in each class; $N$ is the total number of plants; $0,1,2$ and 3 are the symptoms severity indices.

All roots were then packed in plastic bags and stored at $-70^{\circ}$ for further qPCR analysis. The bioassays were conducted twice.

qPCR analyses of $P$. brassicae in plant roots and growing medium

The research was carried out on the roots obtained from plants grown for 10, 20 and 35 days, as described above. In the case of plants growing in non-inoculated growing medium (control), the samples were collected only once, after 35 days. The samples of growing media were collected twice, before sowing and after the experiment was completed. Before DNA extraction, root samples were thoroughly washed with distilled water and blotted on paper towel. Both the roots and growing media were pulverized in liquid nitrogen with mortar and pestle. DNA extraction from plant material was made using DNeasy Plant Mini Kit (Qiagen) and from soil samples using NucleoSpin Soil Kit (Macherey Nagel), according to manufacturer's instructions.

Real-time PCRs were performed using PbF and PbR primers and fluorescently labelled $\mathrm{PbP}$ probe specific for P. brassicae (Wallenhammar et al. 2012) (Table 3). All qPCR amplifications were conducted using a LightCycler 480 Probe Master (Roche) in $25 \mu \mathrm{L}$ volume containing $5 \mu \mathrm{L}$ template DNA, $0.45 \mu \mathrm{L}$ primer $\mathrm{F}$, $0.15 \mu \mathrm{L}$ primer $\mathrm{R}, 0.5 \mu \mathrm{L}$ probe, $12.5 \mu \mathrm{L}$ Master Mix and $6.4 \mu \mathrm{L} \mathrm{H} \mathrm{H}_{2} 0$. DNA extracts were diluted five-fold before analysis and were analysed in triplicate. All reactions were run at $95{ }^{\circ} \mathrm{C}$ for $10 \mathrm{~min}$ followed by 45 cycles at $95{ }^{\circ} \mathrm{C}$ for $15 \mathrm{~s}$ and finally $59{ }^{\circ} \mathrm{C}$ for $1 \mathrm{~min}$. The standard curve for calculating the number of $P$. brassicae genome copies in analysed samples was constructed using plasmid carrying the $P$. brassicae target sequence as a template in qPCR, prepared according to Wallenhammar et al. (2012). A 10-fold dilution series of the plasmid standard were analysed in triplicate using the real-time PCR assay and $\mathrm{Ct}$ values were then plotted against the amount of plasmid DNA to create a standard curve. The pathogen is present in plants and soil in various development forms. To simplify the further calculations, the results of quantitative determination of its DNA copy numbers were presented as equivalents of resting spores, as described by Wallenhammar et al. (2012).

Microscopic observation of $P$. brassicae plasmodia in root hair

The plants were grown in Phytotoxkit test plates (Tigret sp. z o. o.) filled with growing medium inoculated with $P$. brassicae resting spores at density of $10^{7}$ per $\mathrm{mL}$. Ten seeds of each plant genotype studied were sown per one plate in three replications and germinated in growing chamber (Sanyo) with relative humidity of $60 \%$, at $22{ }^{\circ} \mathrm{C}$ in the light for $14 \mathrm{~h}$ and at $20{ }^{\circ} \mathrm{C}$ in the dark for $10 \mathrm{~h}$. Microscopic observations of plants roots were conducted using Olympus BX 41 microscope from 4th to 20th day after sowing. The roots were carefully extracted from the growing medium, washed several times in sterilized water and cut into $1 \mathrm{~cm}$ fragments. Three fragments of each root were examined, beginning from the fragments situated nearest of the seedling's stem. The number of plasmodia containing mature, spherical zoosporangia was estimated in $1 \mathrm{~cm}$ fragments of roots. Average number and maximum number of plasmodia was estimated in 18 pieces of root hairs for each genotype. The experiment was conducted twice for each $P$. brassicae pathotype and each plant genotype.

Data analysis

The data were analysed by standard statistical procedure. Significance of differences between means was established by one-way analysis of variance and Newman-Keuls test at $P<0.05$.

Table 3 Primers and probe sequences used in real-time PCR quantitation of $P$. brassicae (according to Wallenhammar et al. 2012)

\begin{tabular}{ll}
\hline Primer/probe & Sequence $5^{\prime}-3^{\prime}$ \\
\hline $\mathrm{PbF}$ (forward) & AAA CAA CGA GTC AGC TTG AAT GC \\
$\mathrm{PbR}$ (reverse) & TTC GCG CAC AAG CAC TTG \\
$\mathrm{PbP}$ (probe) & CGC GCC ATG CGA CAC TGT TAA ATT G \\
\hline
\end{tabular}




\section{Results}

Glasshouse resistance bioassay - Macroscopic observations

The first galls on roots appeared 20 days after sowing on the susceptible Chinese cabbage 'Granaat' growing in media inoculated with $P$. brassicae pathotypes 2 and 9 and on resistant swede 'Wilhelmsburger' and kale 'Verheul' growing in media inoculated with $\mathrm{Pb} 9$ and on Chinese cabbage 'Bilko $\mathrm{F}_{1}$ ' growing in media inoculated with $\mathrm{Pb} 3$ and $\mathrm{Pb} 9$ (Table 4, Fig. 1). After 35 days from sowing, disease symptoms were visible in almost all genotypes, although their severity varied greatly depending on a pathotype of the pathogen. Swede 'Wilhelmsburger' and headed cabbage 'Kilaton $\mathrm{F}_{1}$ ' were fully resistant to $\mathrm{Pb} 2$, but only partially resistant to $\mathrm{Pb} 3$ and highly susceptible to $\mathrm{Pb} 9$. Chinese cabbage 'Bilko $\mathrm{F}_{1}$ ' showed high resistance to $\mathrm{Pb} 2$ but intermediate to $\mathrm{Pb} 3$ and low to $\mathrm{Pb} 9$. Only turnip line AABBcc showed nearly complete resistance to all the pathotypes of $P$. brassicae tested. Disease symptoms were not observed in all control trays during the entire assay.

qPCR analyses of $P$. brassicae in plant roots and growing medium

The pathogen was present in the roots of all the tested genotypes grown in media inoculated with pathotypes 2 , 3 and 9 on all sampling times (Table 5). In the case of $\mathrm{Pb} 2$, the lowest quantity of spores was observed in turnip line AABBcc. After 35 days the highest quantity of spores was observed in the roots of kale 'Verheul' and headed cabbage 'Bindsachsener' and in the susceptible Chinese cabbage 'Granaat'. In three genotypes: turnip line AABBcc, swede 'Wilhelmsburger' and headed cabbage 'Kilaton $F_{1}$ ' the quantity of spores in roots after 35 days from sowing (third sampling time) have decreased as compared to the quantity of the spores found during the first sampling time, whereas in the remaining genotypes the spore quantity in roots increased during this period. In the case of $\mathrm{Pb} 3$, the lowest quantity of spores was observed in turnip line AABBcc, swede 'Wilhelmsburger' and rapeseed 'Mendel $F_{1}$ ' (Table 5). After 35 days the highest quantity of spores was observed in the roots of the four cultivars: resistant headed cabbages 'Bindsachsener' and 'Kilaton $\mathrm{F}_{1}$ ' and Chinese cabbage 'Bilko $F_{1}$ ' and in the susceptible Chinese cabbage 'Granaat'. Between 10th and 35th day the level of spores has decreased in swede 'Wilhelmsburger', but increased in the remaining genotypes, including susceptible Chinese cabbage 'Granaat'. In plants inoculated with $\mathrm{Pb}$, the lowest quantity of spores was observed in turnip line AABBcc and kale 'Verheul' after 35 days (third sampling time). The highest quantity of spores was detected in the roots of clubroot resistant rapeseed 'Mendel $F_{1}$ ', swede 'Wilhelmsburger' and in susceptible Chinese cabbage 'Granaat' (Table 5). The level of spores decreased between 10th and 35th day after sowing in the roots of turnip line AABBcc, kale 'Verheul' and headed cabbage 'Kilaton $F_{1}$ ', but increased in the roots of remaining genotypes. More complicated was the time course of root infection in the case of $\mathrm{Pb} 9$. Analysis of the roots collected after 20 days from sowing showed a decrease of spore numbers in reference to quantity of spores in the roots collected at the first sampling date, but after additional 15 days of growth the quantity of spores increased, in some genotypes even exceeding the quantity detected in the roots after 10 days of growing (Table 5).

At the beginning of the experiment, in all the tested trays there was about $10^{7}$ resting spores in $1 \mathrm{~g}$ of growing medium (Table 6). After 5 weeks of growth of susceptible Chinese cabbage 'Granaat' the highest number of resting spores was observed in growing media infested with all the pathotypes tested. Cultivation of the other tested genotypes contributed to the increase of the number of spores only in the growing media inoculated with pathotypes 2 and 9, which was especially visible in case of turnip line $\mathrm{AABBcc}$ and headed cabbage 'Bindsachsener' grown in the medium infected by $\mathrm{Pb} 2$ as well as in case of swede 'Wilhelmsburger' and rapeseed 'Mendel $F_{1}$ ' grown in medium infected by $\mathrm{Pb} 9$. It was noted that the quantity of spores of $\mathrm{Pb} 3$ decreased after 35 days of growth of all the genotypes in the infested media. The largest decrease was observed in $\mathrm{Pb} 3$ inoculated medium where rapeseed 'Mendel $\mathrm{F}_{1}$ ' was cultivated.

Microscopic observations of $P$. brassicae plasmodia in root hairs of the genotypes tested

The first plasmodia in hair roots appeared within 410 days from sowing the seeds (Fig. 2). The average number of plasmodia in the observed fragments of the roots depended on the plant genotype and on the $P$. brassicae pathotype. For the $\mathrm{Pb} 2$, the highest average 
Table 4 Reaction of Brassica genotypes to P.brassicae pathotypes in macroscopic observation

\begin{tabular}{|c|c|c|c|c|c|c|}
\hline \multirow[t]{4}{*}{ Genotype } & \multicolumn{6}{|c|}{ Disease Index $(\%)$} \\
\hline & \multicolumn{2}{|l|}{$\mathrm{Pb} 2$} & \multicolumn{2}{|l|}{$\mathrm{Pb} 3$} & \multicolumn{2}{|l|}{$\mathrm{Pb} 9$} \\
\hline & \multicolumn{6}{|c|}{ Days after sowing } \\
\hline & 20 & 35 & 20 & 35 & 20 & 35 \\
\hline B. rapa var. capitata line AABBcc & $0 \mathrm{a}$ & $3 \mathrm{a}$ & $0 \mathrm{a}$ & $1 \mathrm{a}$ & $0 \mathrm{a}$ & $4 \mathrm{a}$ \\
\hline B. napus var. rapifera $\mathrm{cv}$. Wilhelmsburger & $0 \mathrm{a}$ & $0 \mathrm{a}$ & $0 \mathrm{a}$ & $20 \mathrm{~b}$ & $10 \mathrm{~b}$ & $100 \mathrm{c}$ \\
\hline B. oleracea var. capitata $\mathrm{cv}$. Bindsachsener & $0 \mathrm{a}$ & $80 \mathrm{~b}$ & $0 \mathrm{a}$ & $66 \mathrm{e}$ & $0 \mathrm{a}$ & $66 \mathrm{bc}$ \\
\hline B. oleracea var. acephala subvar. lacinata $\mathrm{cv}$. Verheul & $0 \mathrm{a}$ & $71 \mathrm{~b}$ & $0 \mathrm{a}$ & $46 \mathrm{~d}$ & $2 \mathrm{a}$ & $40 \mathrm{~b}$ \\
\hline B. oleracea var. capitata $\mathrm{cv}$. Kilaton $\mathrm{F}_{1}$ & $0 \mathrm{a}$ & $0 \mathrm{a}$ & $0 \mathrm{a}$ & $68 \mathrm{f}$ & $0 \mathrm{a}$ & $72 \mathrm{bc}$ \\
\hline B. rapa subsp. pekinensis cv. Bilko $\mathrm{F}_{1}$ & $0 \mathrm{a}$ & $7 \mathrm{a}$ & $2 \mathrm{~b}$ & $66 \mathrm{e}$ & $2 \mathrm{a}$ & $80 \mathrm{c}$ \\
\hline B. napus var. napus cv. Mendel $\mathrm{F}_{1}$ & $0 \mathrm{a}$ & $21 \mathrm{a}$ & $0 \mathrm{a}$ & $32 \mathrm{c}$ & $0 \mathrm{a}$ & $100 \mathrm{c}$ \\
\hline B. rapa ssp. pekinensis cv. Granaat & $6 \mathrm{~b}$ & $100 \mathrm{c}$ & $0 \mathrm{a}$ & $100 \mathrm{~g}$ & $47 \mathrm{c}$ & $100 \mathrm{c}$ \\
\hline
\end{tabular}

Means in columns followed by the same letter do not differ at $\mathrm{P}<0.05$ based on Newman-Keuls test

and maximum number of plasmodia was observed in root hairs of turnip line AABBcc and headed cabbage 'Kilaton $\mathrm{F}_{1}$ '. The lowest average number of plasmodia was observed in root hairs of kale 'Verheul' and the lowest maximum number of plasmodia was recorded in swede 'Wilhelmsburger'. In the case of $\mathrm{Pb} 3$ the highest average and maximum number of plasmodia was observed in root hairs of kale 'Verheul'. Also, high maximum number of plasmodia in root hairs was observed in Chinese cabbage 'Bilko $\mathrm{F}_{1}$ '. The lowest number of plasmodia was observed in case of swede 'Wilhelmsburger'. For $\mathrm{Pb} 9$, the highest average and maximum number of plasmodia was observed in root hairs of rapeseed 'Mendel $\mathrm{F}_{1}$ '. Similarly, high average and maximum numbers of plasmodia per $1 \mathrm{~cm}$ of root were observed in turnip line AABBcc
(Table 7). The lowest number of plasmodia was observed in case of kale 'Verheul'.

\section{Discussion and conclusions}

Resistance to clubroot is one of the most important objectives in Brassica breeding programmes. The main problems in this task is large variations of pathogenicity of Plasmodiophora brassicae, which can quickly break the resistance of cultivars intended for planting on large areas (LeBoldus et al. 2012; Tanaka and Ito 2013; Diederichsen et al. 2014). Therefore, in clubroot resistance breeding programmes it is of a great importance to evaluate the available sources of resistance to most, or at least to most of locally occurring pathotypes of
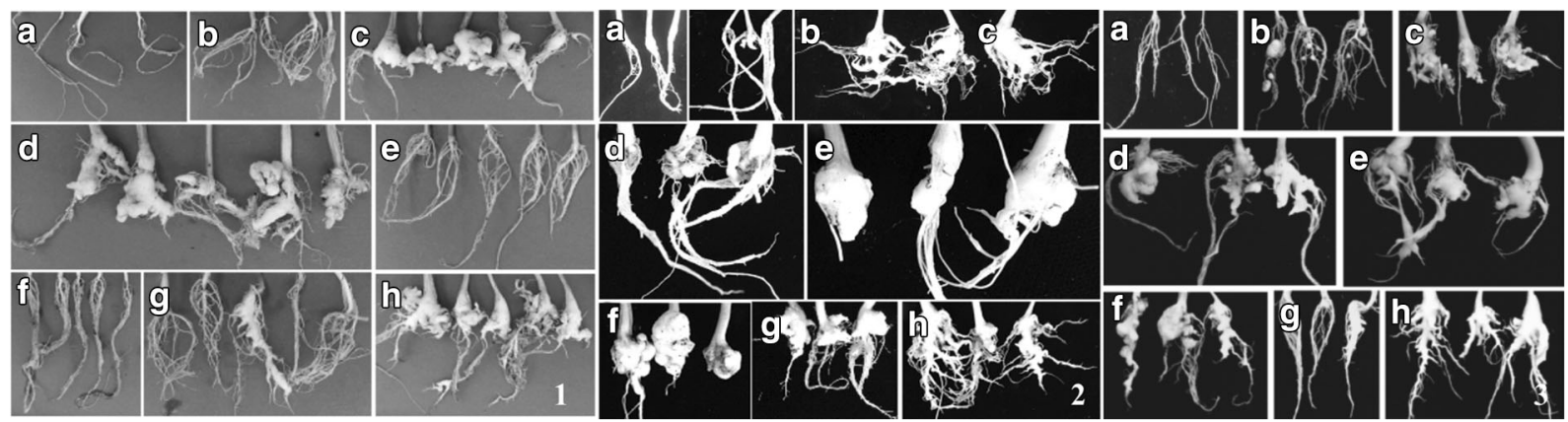

Fig. 1 Root systems of the plant genotypes tested after 35 days after sowing: 1 - pathotype 2; 2 - pathotype $9 ; 3$ - pathotype 3 (a - B rapa line AABBcc, b-B. napus cv. Wilhelmsburger, c - B. oleracea $\mathrm{cv}$.
Bindsachsener, d - B. oleracea cv. Verheul, e - B. oleracea cv. Kilaton $\mathrm{F}_{1}, \mathbf{f}-$ B. rapa $c$. Bilko $\mathrm{F}_{1}, \mathbf{g}-$ B. napus $\mathrm{cv}$. Mendel $\mathrm{F}_{1}, \mathbf{h}$ - B. rapa ssp. pekinensis cv. Granaat) 


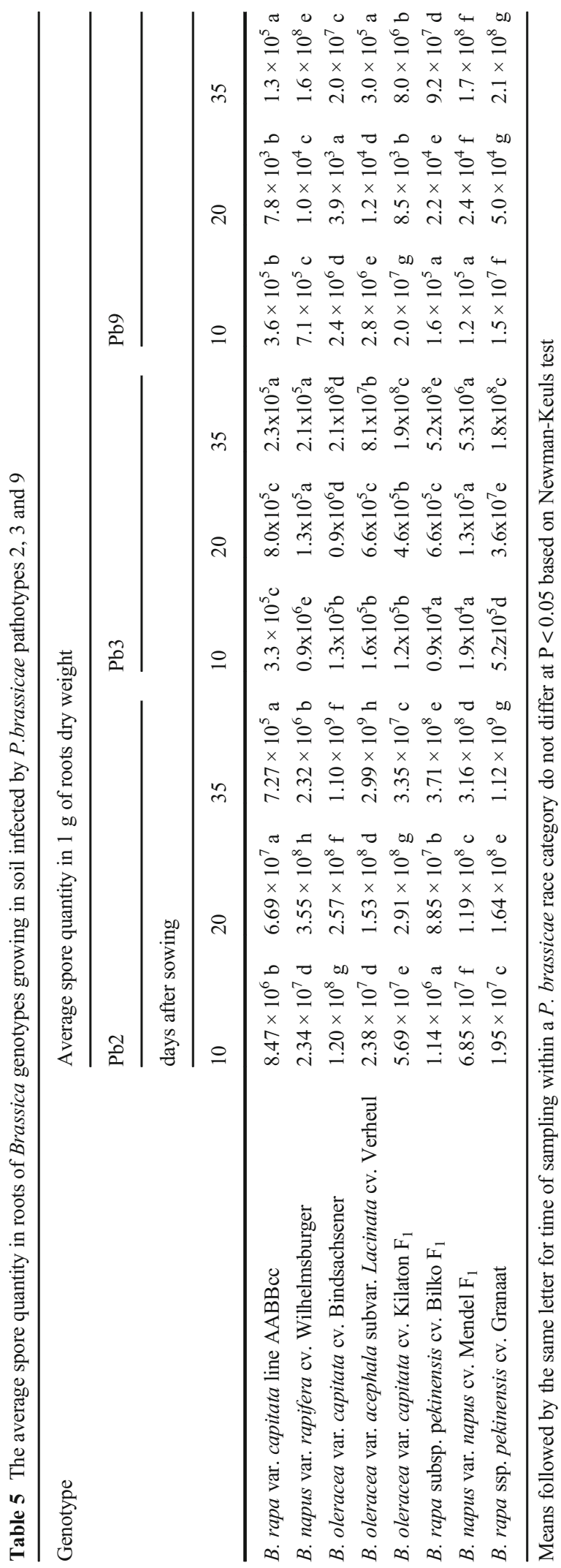


P.brassicae and apply gene pyramiding approach. In Poland, research on clubroot resistance was concentrated on vegetable Brassicas and on winter oilseed rape, where disease causes considerable losses (Robak and Gidelska 2009; Kurowski et al. 2009), among others due to high infestation of local soils by P.brassicae (Kopecký et al. 2012; Jędryczka et al. 2014).

The genotypes selected for the study have been found in other researches as resistant to a number of $P$. brassicae pathotypes, but our results indicate that in most of them resistance was broken down by the Polish isolates of the pathogen. Only genotypes with ID of less than 20 are considered as highly resistant (Chytilová and Dušek 2007). In our experiments only B. rapa var. capitata line AABBcc (ECD 03) fulfilled this criterion in reference to all three $P$. brassicae pathotypes isolated in Poland. High resistance of this genotype confirms earlier results of Kuginuki et al. (1999), Donald et al. (2006) and Hasan et al. (2012).

Some of the other genotypes tested were resistant only to selected pathotypes, e.g. B. napus var. rapifera 'Wilhelmsburger' to $\mathrm{Pb} 2$ and $\mathrm{Pb} 3$, B. oleracea var. capitata 'Kilaton $\mathrm{F}_{1}$ ' and $B$. rapa subsp. pekinensis 'Bilko $\mathrm{F}_{1}$ ' to $\mathrm{Pb} 2$. High resistance of $B$. napus var. rapifera 'Wilhelmsburger' to $P$. brassicae pathotype 3 found in our experiments confirms earlier results of Kuginuki et al. (1999), Donald et al. (2006) and Hasan et al. (2012). But research partially contradicts results of other studies. Headed cabbage 'Kilaton $\mathrm{F}_{1}$ ' in our experiments was fully resistant to $\mathrm{Pb} 2$ infection, but was highly susceptible to $\mathrm{Pb} 3$ and $\mathrm{Pb} 9$ (IDs 68 and 72, respectively), but in the threeyear field studies done by in Polish conditions by Cebula et al. (2010) this cultivar was fully resistant to clubroot. However, they have not determined the pathotype(s) of $P$. brassicae infesting the experimental plots. $B$. oleracea var. acephala 'Verheul', which according to Cao et al. (2014) was highly to moderately resistant to $\mathrm{Pb} 3$, in our experiments was highly to moderately susceptible to all the pathotypes tested (IDs 71, 46 and 40 in reference to $\mathrm{Pb} 2$, $\mathrm{Pb} 3$ and $\mathrm{Pb} 9$, respectively). Also B. napus var. napus 'Mendel $\mathrm{F}_{1}$ ', which carries a major dominant gene and two recessive genes conferring clubroot resistance and, according to Diederichsen et al. (2006) and Rahman et al. (2014), is fully resistant to majority of $P$. brassicae pathotypes dominant in Europe, in our research it was moderately or highly susceptible to Polish isolates of $\mathrm{Pb} 3$ and $\mathrm{Pb} 9$ (IDs 32 and 100, respectively). This shows that the pathotype of $P$. brassicae isolates collected in various areas and determined using differential sets does not 

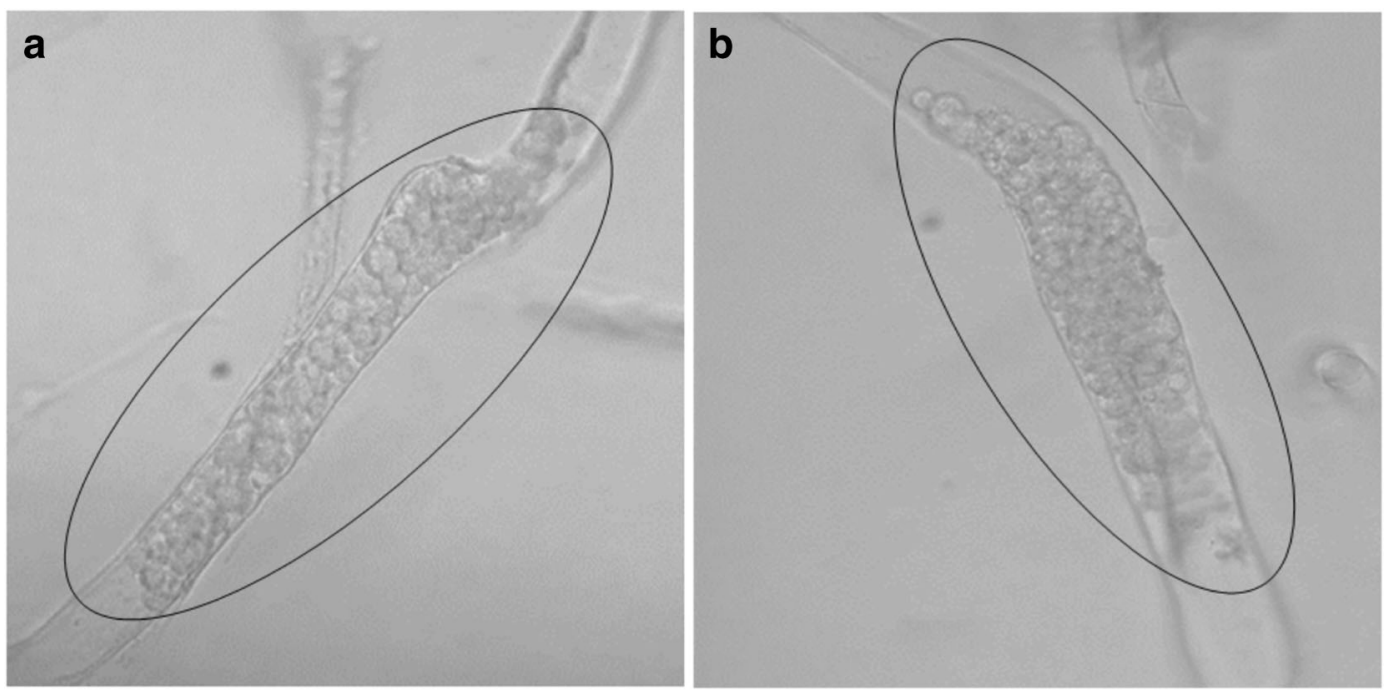

Fig. 2 Exemplary picture of mature plasmodia (zoosporangia) in root hairs of B. oleracea cv. Kilaton $\mathrm{F}_{1}(\mathbf{a})$ and $B$. napus $\mathrm{cv}$. Mendel $\mathrm{F}_{1}$ (b) grown in the medium inoculated with $\mathrm{Pb} 2$

necessarily reflect its actual level of virulence toward various Brasssica genotypes. Thus, prior to the introduction for cultivation of new resistant Brassica species/ cultivars or selecting them as a source of resistance traits in breeding programmes their resistance/susceptibility to local Plasmodiophora brassicae isolates shall be tested before hand, irrespective of the pathotypes of the pathogen determined elsewhere with differential set.

In the available literature there is no information about resistance of the genotypes tested in our study to P. brassicae pathotype 9. According to our best knowledge this is the first such a report.

Our research shows that of seven clubroot-resistant genotypes of Brassica evaluated, only B. rapa var. capitata line AABBcc, B. napus var. rapifera 'Wilhelmsburger', B. oleracea var. capitata 'Kilaton $\mathrm{F}_{1}$ ' and B. rapa subsp. pekinensis 'Bilko $\mathrm{F}_{1}$ ' can be recommended as a source of clubroot resistance in Brassica breeding programmes or for cultivation in low- to moderately-infested soils in Poland.

In our study, the primary root infection was not correlated with plant's resistance to clubroot. In fact, the root hairs of $B$. rapa var. capitata line $\mathrm{AABBcc}$, which was resistant to all the pathotypes tested, had the highest population of P. brassica plasmodia of all the genotypes tested. This confirms the findings of Kageyama and Asano (2009) who suggested that susceptibility of root hairs to

Table 7 The average and maximum number of plasmodia containing mature, spherical zoosporangia observed in the hair roots of seven Brassica genotypes growing in medium infested with different P.brassicae pathotypes

\begin{tabular}{|c|c|c|c|c|c|c|}
\hline \multirow[t]{2}{*}{ Genotype } & \multicolumn{3}{|c|}{$\begin{array}{l}\text { Average number of plasmodia in root } \\
\text { hairs per } 1 \mathrm{~cm} \text { of root* }\end{array}$} & \multicolumn{3}{|c|}{$\begin{array}{l}\text { Maximum number of plasmodia in root } \\
\text { hairs per } 1 \mathrm{~cm} \text { of root }\end{array}$} \\
\hline & $\mathrm{Pb} 2$ & $\mathrm{~Pb} 3$ & $\mathrm{~Pb} 9$ & $\mathrm{~Pb} 2$ & $\mathrm{~Pb} 3$ & $\mathrm{~Pb} 9$ \\
\hline B. rapa var. capitata line $\mathrm{AABBcc}$ & 17.6 & 6.1 & 15.0 & 48 & 23 & 40 \\
\hline B. napus var. rapifera $\mathrm{cv}$. Wilhelmsburger & 5.8 & 2.3 & 5.7 & 11 & 5 & 19 \\
\hline B. oleracea var. capitata $\mathrm{cv}$. Bindsachsener & 6.4 & 6.1 & 2.1 & 17 & 18 & 11 \\
\hline B. oleracea var. acephala subvar. lacinata cv. Verheul & 5.2 & 14.6 & 1.3 & 28 & 38 & 5 \\
\hline B. oleracea var. capitata $\mathrm{cv}$. Kilaton $\mathrm{F}_{1}$ & 16.8 & 10.0 & 2.8 & 44 & 31 & 8 \\
\hline B. rapa subsp. pekinensis cv. Bilko $\mathrm{F}_{1}$ & 9.1 & 12.6 & 4.0 & 35 & 39 & 18 \\
\hline B. napus var. napus cv. Mendel $\mathrm{F}_{1}$ & 7.2 & 14.0 & 25.0 & 20 & 15 & 63 \\
\hline
\end{tabular}

*average number of plasmodia in 18 pieces of root hairs for each genotype 
infection cannot be correlated with susceptibility of cortical cells and resultant galls formation. As reported by McDonald et al. (2014), primary infection can occur in both susceptible and resistant host cultivar, and even in non-host plants, however secondary plasmodia frequently would not mature in resistant genotypes and are unable to produce resting spores. This hypothesis is confirmed by our findings that only in the resistant cultivar $B$. rapa var. capitata line AABBcc the number of spores in the roots decreased in the course of infection with all the tested pathotypes of pathogen. Our microscopic observation showed that the emergence of the first mature plasmodia in root hairs depends on the genotype of the tested plants. It was noted that the average number of plasmodia in the root depended both on the plant genotype and on the pathotype $P$. brassicae. In the case of pathotype 2 the appearance of mature plasmodia containing spherical sporangia was observed earlier than in the case of $\mathrm{Pb} 3$ and $\mathrm{Pb} 9$. Morgner and Sacristán (1995) also reported colonization of clubroot-resistant Brassica genotypes by $P$. brassicae. In their quantitative study pathogen structures were observed 12 days after inoculation of B. napus and B. oleracea. Voorrips (1992) demonstrated large differences in the levels of primary root hair infection among thirteen host genotypes with varying levels of resistance, however did not observe correlation between resistance to root hair infection and resistance to clubroot. According to this author, only complete resistance to root hair infection would confer resistance to clubroot.

It is widely believed that the clubroot incidence can be limited by planting the bait, decoy or catch plants, which can stimulate germination of resting spores and thus reduce their quantity of in the soil (Yamagishi et al. 1986; Murakami et al. 2000). According to Ikegami (1985), cultivation of clubroot-resistant Japanese radish (Raphanus sativus) during 5 years resulted in a considerable decrease of resting spore populations in the soil. Resting spores population was also slightly reduced after two cycles of other cruciferous nonhost crops (Ahmed et al. 2011). However, in our research, cultivation of the clubroot-resistant genotypes contributed to the increase of the number of spores in the growing media inoculated with pathotypes 2 and 9 . These results suggest that the cultivation of resistant cultivars in heavily infected areas does not guarantee a reduction of the soil infestation with $P$. brassicae resting spores shall not be recommended as a measure to control clubroot.

Acknowledgements Special thanks to Dr. Piotr Kamiński from Department of Genetics and Breeding Vegetable Plants Research Institute of Horticulture for sharing seeds of selected Brassica genotypes.

This work was supported by the Ministry of Agriculture and Rural Development within Basic research for the biological progress in plant production programme - Task 99.

Compliance with ethical standards This article does not contain any studies with human or animal subjects performed by any of the authors.

Conflict of interest All authors listed have contributed to the work, have read the manuscript and declare that there are no potential conflicts of interest.

Open Access This article is licensed under a Creative Commons Attribution 4.0 International License, which permits use, sharing, adaptation, distribution and reproduction in any medium or format, as long as you give appropriate credit to the original author(s) and the source, provide a link to the Creative Commons licence, and indicate if changes were made. The images or other third party material in this article are included in the article's Creative Commons licence, unless indicated otherwise in a credit line to the material. If material is not included in the article's Creative Commons licence and your intended use is not permitted by statutory regulation or exceeds the permitted use, you will need to obtain permission directly from the copyright holder. To view a copy of this licence, visit http://creativecommons. org/licenses/by/4.0/.

\section{References}

Ahmed, H. U., Hwang, S. F., Strelkov, S. E., Gossen, B. D., Peng, G., Howard, R. J., \& Turnbull, G. D. (2011). Assessment of bait crops to reduce inoculum of clubroot (Plasmodiophora brassicae) of canola. Canadian Journal of Plant Science, 91(3), 545-551. https://doi.org/10.4141/CJPS10200.

Buczacki, S. T., Toxopeus, H., Mattusch, P., Johnston, T. D., Dixon, G. R., \& Hobalth, L. A. (1975). Study of physiologic specialization in Plasmodiophora brassicae. Proposals for attempted rationalization through an international approach. Transactions of the British Mycological Society, 65, 295-303.

Cao, T., Rennie, D. C., Manolii, V. P., Hwang, S. F., Falak, I., \& Strelkov, S. E. (2014). Quantifying resistance to Plasmodiophora brassicae in Brassica hosts. Plant Pathology, 63, 715-726. https://doi.org/10.1111/ppa.12113.

Cebula, S., Mazur, S., \& Kalisz, A. (2010). Evaluation of productive value of several white cabbage cultivars resistant to 
clubroot (Plasmodiophora brassicae Wor.). Ecological Chemistry and Engineering A, 17(9), 1083-1088.

Chytilová, V. \& Dušek, K. (2007). Methodology of testing the resistance of cruciferous crops to clubroot. Methodology for practice. In Czech: Metodika testování odolnosti brukvovitých plodin $\mathrm{k}$ nádorovitosti. Metodika pro praxi. Výzkumný ústav rostlinné výroby, Praha, VÚRV.

Deora, A., Gossen, B. D., \& McDonald, M. R. (2013). Cytology of infection, development and expression of resistance to Plasmodiophora brassicae in canola. Annals of Applied Biology, 163, 56-71. https://doi.org/10.1111/aab.12033.

Diederichsen, E., Beckmann, J., Schondelmeier, J., \& Dreyer, F. (2006). Genetics of clubroot resistance in Brassica napus 'Mendel'. Acta Horticulturae, 706, 307-312. https://doi. org/10.17660/ActaHortic.2006.706.35.

Diederichsen, E., Frauen, M., \& Ludwig-Muller, J. (2014). Clubroot disease management challenges from a German perspective. Canadian Journal of Plant Pathology, 36, 8598. https://doi.org/10.1080/07060661.2013.861871.

Dixon, G. R. (2009). Plasmodiophora brassicae in its environment. Journal of Plant Growth Regulation, 28, 212-228.

Dixon, G. R. (2014). Clubroot (Plasmodiophora brassicae Woronin) - an agricultural and biological challenge worldwide. Canadian Journal of Plant Pathology, 36, 5-18. https://doi.org/10.1080/07060661.2013.875487.

Donald, E. C., Cross, S. J., Lawrence, J. M., \& Porter, I. J. (2006). Pathotypes of Plasmodiophora brassicae, the cause of clubroot, in Australia. Annals of Applied Biology, 148, 239-244. https://doi.org/10.1111/j.1744-7348.2006.00062.x.

Hasan, M. J., Strelkov, S. E., Howard, R. J., \& Rahman, H. (2012). Screening of Brassica germplasm for resistance to Plasmodiophora brassicae pathotypes prevalent in Canada for broadening diversity in clubroot resistance. Canadian Journal of Plant Science, 92, 501-515. https://doi. org/10.4141/CJPS2010-006.

Hwang, S. F., Ahmed, H. U., Zhou, Q., Turnbull, G. D., Strelkov, S. E., Gossen, B. D., \& Peng, G. (2015). Effect of host and non-host crops on Plasmodiophora brassicae resting spore concentrations and clubroot of canola. Plant Pathology, 64, 1198-1206. https://doi.org/10.1111/ppa.12347.

Ikegami, H. (1985). Decrease of clubroot fungus by cultivation of different crops in heavily infested soil. Research Bulletin of the Faculty of Agriculture, Gifu University, 50, 19-32.

Jędryczka, M., Kasprzyk, I., Korbas, M., Jajor, E., \& Kaczmarek, J. (2014). Infestation of polish agricultural soils by Plasmodiophora brassicae along the Polish-Ukrainian border. Journal of Plant Protection Research, 54(3), 238-241.

Kageyama, K., \& Asano, T. (2009). Life cycle of Plasmodiophora brassicae. Journal of Plant Growth Regulation, 28, 203211.

Kopecký, P., Doležalová, I., Duchoslav, M., \& Dušek, K. (2012). Variability in resistance to Clubroot in European cauliflower cultivars. Plant Protection Science, 48(4), 156-161.

Kuginuki, Y., Yoshikawa, H., \& Hirai, M. (1999). Variation in virulence of Plasmodiophora brassicae in Japan tested with clubroot resistant cultivars of Chinese cabbage (Brassica rapa L. ssp. pekinensis). European Journal of Plant Pathology, 105, 327-332.

Kurowski, T. P., Majchrzak, B., \& Kowalska, E. (2009). The effectiveness of the biological control of clubroot (Plasmodiophora brassicae) in Brassicaceae plants. Phytopathology, 52, 5-12.
LeBoldus, J. M., Manolii, V. P., Turkington, T. K., \& Strelkov, S. E. (2012). Adaptation to Brassica host genotypes by a singlespore isolate and population of Plasmodiophora brassicae (Clubroot). Plant Disease, 96, 833-838. https://doi. org/10.1094/PDIS-09-11-0807.

McDonald, M. R., Sharma, K., Gossen, B. D., Deora, A., Feng, J., \& Hwang, S.-F. (2014). The role of primary and secondary infection in host response to Plasmodiophora brassicae. Phytopathology, 104, 1078-1087. https://doi.org/10.1094 /PHYTO-07-13-0189-R.

Morgner, M., \& Sacristán, M. D. (1995). Quantitative determination of colonization by Plasmodiophora brassicae (Wor.) in Brassica napus and Brassica oleracea. Cruciferae Newsletter, 17, 80-81.

Murakami, H., Tsuhima, S., Akimoto, T., Murakami, K., Goto, I., \& Shishido, Y. (2000). Effects of growing leafy daikon (Raphanus sativus) on populations of Plasmodiophora brassicae (Clubroot). Plant Pathology, 49, 584-589. https://doi.org/10.1046/j.1365-3059.2000.00495.x.

Peng, G., Lahlali, R., Hwang, S. F., Pageau, D., Hynes, R. K., McDonald, M. R., Gossen, B. D., \& Strelkov, S. E. (2014). Crop rotation, cultivar resistance, and fungicides/biofungicides for managing Clubroot (Plasmodiophora brassicae) on canola. Canadian Journal of Plant Pathology, 36, 99-112. https://doi. org/10.1080/07060661.2013.860398.

Rahman, H., Peng, G., Yu, F., Falk, K. C., Kulkarni, M., \& Selvaraj, G. (2014). Genetics and breeding for clubroot resistance in Canadian spring canola (Brassica napus L.). Canadian Journal of Plant Pathology, 36, 122-134. https://doi.org/10.1080/07060661.2013.862571.

Robak, J. (1991). Variability of Plasmodiophora brassicae Wor. pathotypes occurring in Poland and their pathogenicity to Brassica oleracea cultivars and breeding lines. Post-doctoral thesis 6, Institute of Vegetable Crops, Skierniewice, 1-60.

Robak, J., \& Gidelska, A. (2009). Epidemiology and new possibility of control of Plasmodiophora brassicae causal agent of clubroot of cruciferous crops in Poland. Progress in Plant Protection, 49(1), 268-274.

Strelkov, S. E., \& Hwang, S. F. (2014). Clubroot in the Canadian canola crop: 10 years into the outbreak. Canadian Journal of Plant Pathology, 36, 27-36. https://doi.org/10.1080 /07060661.2013.863807.

Strelkov, S. E., Tewarii, J. P., \& Smith-Degenhardt, E. (2006). Characterization of Plasmodiophora brassicae populations from Alberta, Canada. Canadian Journal of Plant Pathology, 28, 467-474. https://doi.org/10.1080/07060660609507321.

Tanaka, S., \& Ito, S. (2013). Pathogenic and genetic diversity in Plasmodiophora brassicae (clubroot) from Japan. Journal of General Plant Pathology, 79(5), 297-306. https://doi. org/10.1007/s10327-013-0456-4.

Voorrips, R. E. (1992). Root hair infection by Plasmodiophora brassicae in clubroot-resistant and susceptible genotypes of Brassica oleracea, B. rapa and B. napus. Netherlands Journal of Plant Pathology, 98, 361-368.

Wallenhammar, A. C. (1996). Prevalence of Plasmodiophora brassicae in a spring oilseed rape growing area in Central Sweden and factors influencing soil infestation levels. Plant Pathology, 45, 710-719. https://doi.org/10.1046/j.1365-3059.1996.d01-173.x.

Wallenhammar, A. C., Almquist, C., Soderstrom, M., \& Jonsson, A. (2012). In-field distribution of Plasmodiophora brassicae 
measured using quantitative real-time PCR. Plant Pathology, 61, 16-28. https://doi.org/10.1111/j.1365-3059.2011.02477.x.

Williams, P. H. (1966). A system for the determination of races of Plasmodiophora brassicae that infect cabbage and rutabaga. Phytopathology, 56, 624-626.
Yamagishi, H., Yoshikawa, H., Ashizawa, M., Hida, K., \& Yur, S. (1986). Effects of resistance plants as a catch crop on the reduction of resting spores of clubroot (Plasmodiophora brassicae worn.) in soil. Journal of the Japanese Society for Horticultural Science, 54(4), 460-466. https://doi.org/10.2503 jjshs.54.460. 